Article

\title{
Hydrogen-Assisted Sputtering Growth of TiN on Ceramic Substrates
}

\author{
Jaewon Choi ${ }^{1}$, Wonjin Jeon ${ }^{1}$, Dongjin Kang ${ }^{2}$, Doowon Kang ${ }^{2}$ and Jungyol Jo ${ }^{1, *}$ \\ 1 Department of Electrical and Computer Engineering, Ajou University, Suwon 16499, Korea; \\ poetik@ajou.ac.kr (J.C.); wiseboy48@ajou.ac.kr (W.J.) \\ 2 Smart Electronics Inc., 87 Samdongro, Ulsan 44956, Korea; djkang@smart-ele.co.kr (D.K.); \\ dwkang@smart-ele.co.kr (D.K.) \\ * Correspondence: jungyol@ajou.ac.kr; Tel.: +82-10-3302-6503
}

Received: 20 March 2019; Accepted: 15 April 2019; Published: 17 April 2019

check for updates

\begin{abstract}
Titanium nitride (TiN) has mechanical and electrical characteristics applicable for very large scale integration (VLSI) and discrete electronic devices. This study assessed the effect of hydrogen on sputtering growth of TiN on ceramic substrates. Although ceramic substrate is used in discrete device applications due to its insulating property, ceramic is also porous and contains oxygen and water vapor gases, which can be incorporated into TiN films during growth. In addition, discrete devices are usually packaged in glass sealing at $700{ }^{\circ} \mathrm{C}$, and reaction with the trapped gases can significantly degrade the quality of the TiN film. In order to evaluate ways to minimize the effects of these gases on TiN, hydrogen gas was introduced during sputtering growth. The main hypothesis was that the hydrogen gas would react with oxygen to lower the oxygen density in the vacuum chamber, which would suppress the effects of the trapped gases in the ceramic and ultimately improve the quality of the TiN film. Improvements in TiN quality were confirmed by X-ray diffraction (XRD), energy dispersive spectroscopy (EDS), and resistance measurements. During the glass-sealing process, $\mathrm{N}_{2}$-purging at $400{ }^{\circ} \mathrm{C}$ was effective at keeping the TiN in a low resistance state. These results show that introducing hydrogen gas during sputtering growth could solve the problems caused by ceramic substrates.
\end{abstract}

Keywords: annealing; ceramic substrate; hydrogen; sputtering; titanium nitride; X-ray diffraction

\section{Introduction}

Titanium nitride (TiN) is an extremely hard material with high electrical conductivity. In very large scale integration (VLSI) circuits, TiN has been used in many applications as a diffusion barrier, adhesion layer, and electrode [1]. Recently, TiN has received attention as an electrode for use in rechargeable batteries [2-4]. TiN can be deposited in various ways, including direct current (DC) sputtering [5,6], atomic layer deposition [1], pulsed laser deposition [7], and plasma spraying [8]. For industry applications, DC sputtering is a good method due to its low cost. This method can deposit films of high purity and uniformity on various substrates. TiN is also a good material for discrete electronic devices. However, the use of TiN as a discrete device poses additional problems compared to VLSI application due to its method of manufacturing.

TiN for discrete devices is usually grown on ceramic substrates, since the insulating property of the ceramic substrate is highly desirable for device isolation. The ceramic substrate is made of porous material such as $\mathrm{Al}_{2} \mathrm{O}_{3}$ powder, which is a strong absorber of $\mathrm{O}_{2}$ and $\mathrm{H}_{2} \mathrm{O}$. These absorbed gases can degrade the quality of TiN films during sputtering growth. Discrete devices are sealed in a glass tube at high temperature, and this step can also encourage reaction between Ti and gases trapped in the 
ceramic substrate. Therefore, in reactive sputtering using a Ti metal target and $\mathrm{N}_{2}$ gas, residual oxygen in the chamber is an important factor in determining the quality of the TiN film.

One important complication in reactive sputtering is change in the target surface condition or target contamination [9]. When gases react with the metallic Ti target, the target surface can become covered with oxide or nitride. This results in a decreased flow of Ti from the target. Another problem in reactive sputtering is a mid-course reaction, which occurs before the Ti atom reaches the substrate. When there is too much gas in the chamber, Ti atoms emitted from the target are consumed by the ionized gases, and TiN growth at the substrate is significantly decreased. Therefore, trapped gases in the ceramic cause two problems: Ti supply from the target decreases as a result of the target contamination, and a large portion of Ti flow is lost in vacuum due to the mid-course reaction. Introducing hydrogen gas during sputtering growth could potentially address these problems, as a large portion of the ionized oxygen would react with the hydrogen, thereby decreasing oxygen density in the vacuum. The function of hydrogen during sputtering has been investigated before [10,11]. In Reference [10], $\mathrm{ArH}^{+}$energy distributions showed a large high-energy tail, which increased the sputtering rate. In Reference [11], it was explained that hydrogen converted the insulating surface of the metal target into a conductive surface, and arcing was prevented in DC sputtering.

Another source of problems associated with discrete devices occurs during glass sealing, during which the device is encapsulated in a specific gas mixture. Discrete devices are usually sealed in a vacuum-tight glass tube to prevent degradation by oxygen and moisture. The contact between glass and metal electrode is formed at $700^{\circ} \mathrm{C}$. Since TiN is oxidized at $800{ }^{\circ} \mathrm{C}$, it is important to remove oxygen before the sealing process $[12,13]$. In practical applications using the ceramic substrates, however, it is difficult to remove all trapped oxygen. Therefore, it is necessary to develop a new method to minimize the effect of residual oxygen during the sealing process.

$\mathrm{TiN}$ can be used for a variety of electronic devices working in harsh environments. One example is a surge absorber used to protect electronic devices from voltage spikes [14]. Surge absorbers connected to a main circuit protect the circuit by flowing a large current when high voltage surges strike the electric leads. When high voltage is applied to a surge absorber, electric discharge is initiated between two narrowly-spaced electrodes, and a large current flows through the ionized gas. The electrodes can be made with either bulk metal or deposited films. Due to manufacturing costs, a film-type surge absorber is preferred. Normal metals in film-type surge absorbers change shape after repeated discharges, and their discharge characteristics deteriorate. TiN is a good choice for the electrodes in the film-type surge absorber due to its high hardness. However, new methods of adjusting growth parameters in reactive sputtering are needed to optimize its fabrication process. This work assessed whether introducing hydrogen gas in sputtering growth could neutralize the effect of trapped oxygen and remove impurities on the target surface, ultimately leading to a TiN film of an improved quality.

\section{Materials and Methods}

Figure 1 shows a schematic diagram of the DC sputtering system and images of TiN films grown on ceramic rods. Ceramic rods (Dong Guan Feng Li Electronics, Dongguan, China) made of $\mathrm{Al}_{2} \mathrm{O}_{3}$ powder were preheated in vacuum at $400{ }^{\circ} \mathrm{C}$ before sputtering growth. A rotating barrel was utilized to deposit TiN on ceramic rods placed at the bottom of the barrel. Ceramic rods were cylindrical in shape, with a diameter of $1.7 \mathrm{~mm}$ and length of $5.5 \mathrm{~mm}$. The rotation of the barrel caused mixing of the ceramic rods, and the TiN film was uniformly deposited onto the cylindrical surfaces of the rods. Three hundred grams of ceramic rods were used for one growth. The distance between the target and ceramic holder was $12 \mathrm{~cm}$. 


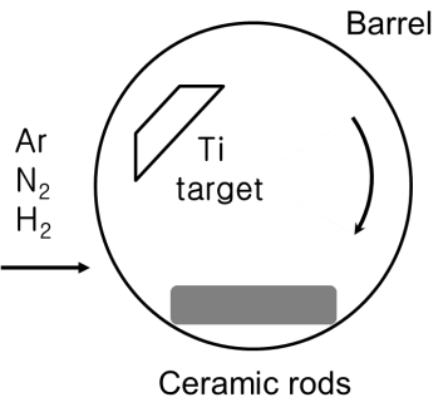

(a)

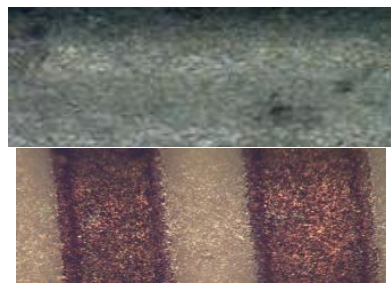

(b)

Figure 1. (a) Schematic diagram of the direct current (DC) sputtering system utilized for TiN deposition on ceramic rods. (b) TiN films grown on ceramic rods. The upper one was grown with $\mathrm{N}_{2}$ only. The lower one was grown with $\mathrm{N}_{2}+\mathrm{H}_{2}$, etched for characterization.

For X-ray diffraction (XRD) and energy dispersive spectroscopy (EDS) measurements, glass or sapphire substrates (iNexus, Seongnam, Korea) were used to grow TiN films. Growth time was $30 \mathrm{~min}$ for glass and sapphire substrates, and $2 \mathrm{~h}$ for ceramic rods. There was no intentional heat supplied, but after a $2 \mathrm{~h}$ of growth, the barrel temperature rose to $120^{\circ} \mathrm{C}$. A rectangular Ti metal plate $\left(45 \times 15 \mathrm{~cm}^{2}\right)$ was used as the target (THIFINE, Incheon, Korea). A cryopump (Genesis Vacuum Technology, Pyongtaek, Korea) was used to pump the chamber. The chamber was initially pumped to $10^{-3} \mathrm{~Pa}$, and $\mathrm{Ar}$ and $\mathrm{H}_{2}$ gases were subsequently introduced. After the plasma became stabilized, $\mathrm{N}_{2}$ gas was introduced. The pressure during growth was $0.3 \mathrm{~Pa}$. Constant power of $1800 \mathrm{~W}$ was supplied for DC sputtering. The target voltage during growth was $-480 \mathrm{~V}$ with current of $\sim 3 \mathrm{~A}$. XRD was measured by a diffractometer (Rigaku Ultima III, Tokyo, Japan) using $\mathrm{Cu} \mathrm{K} \alpha$ line as a source. EDS was measured by a scanning electron microscope (JEOL JSM-6380, Tokyo, Japan).

\section{Results}

Initial growth without $\mathrm{H}_{2}$ produced black or gray TiN films instead of gold colored TiN. The grown films showed high resistance, and XRD data did not show strong peaks. EDS results showed a high nitrogen concentration, with Ti: $\mathrm{N}$ ratio of approximately 20:80. These results suggested that the target surface was heavily coated with impurities and that Ti emission from the target was very small.

Next, three different gas flows were used for the growth of subsequent samples (Table 1). Sample A was grown without $\mathrm{H}_{2}$, and a small flow of $\mathrm{N}_{2}$ was used. For Samples $B$ and $\mathrm{C}, \mathrm{H}_{2}$ was added during growth. For all samples, Ar flow was fixed at $22 \mathrm{sccm}$. Ti/N ratios were measured by EDS (Table 1). TiN thickness was measured by a profiler from TiN films grown on glass for $30 \mathrm{~min}$. As the ceramic rods were of a cylindrical shape, rod resistance was defined as the resistance measured between the two ends of a cylinder (Table 1).

Table 1. Gas flows, Ti/N ratios, and rod resistances of Samples A, B, and C.

\begin{tabular}{ccccccc}
\hline Sample Name & $\mathbf{N}_{\mathbf{2}}(\mathbf{s c c m})$ & $\mathbf{H}_{\mathbf{2}}(\mathbf{s c c m})$ & Ti (\%) & $\mathbf{N}(\%)$ & Thickness $(\boldsymbol{\mu m})$ & $\operatorname{Rod} \mathbf{R}(\boldsymbol{\Omega})$ \\
\hline A & 1 & 0 & 26.8 & 73.2 & 0.43 & $9 \mathrm{k}$ \\
B & 11 & 8 & 28.1 & 71.9 & 0.55 & 50 \\
C & 8 & 8 & 45.5 & 54.5 & 0.83 & 12 \\
\hline
\end{tabular}

Sample A was gray in color, and Samples B and C had the gold color of TiN. Sample A showed a high $\mathrm{N}$ concentration, and rod resistance was very large. Note that Sample $\mathrm{C}$ had the highest concentration of Ti. $\mathrm{N}_{2}$ flow for Sample B was larger than that of Sample C, and the N concentration was significantly increased. An increase in the flow of $\mathrm{N}_{2}$ was related to the increase of $\mathrm{N}$ concentration in Sample B. 
XRD was measured in the three samples (Figure 2). The lowest curve (Sample A) is XRD of TiN grown without $\mathrm{H}_{2}$. Samples $B$ and $\mathrm{C}$ were grown with $\mathrm{H}_{2}$, and XRD data show strong peaks in these samples. Although Ti concentration in Sample B was similar to that of Sample A, rod resistance of B was much smaller, and strong XRD peaks are shown. These data suggest that the enhanced resistance characteristics of Samples $\mathrm{B}$ and $\mathrm{C}$ are related to the $\mathrm{H}_{2}$ added during sputtering growth. The XRD peak positions from JCPDS $38-1420$ are $36.662^{\circ}(111), 42.596^{\circ}(200), 61.812^{\circ}(220)$, and $74.068^{\circ}(311)$.

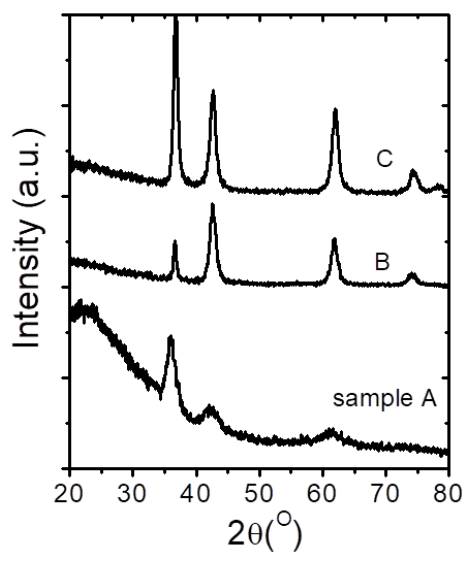

Figure 2. X-ray diffraction (XRD) measured in Samples A, B, and C, grown on glass substrates. The four peaks are $36.8^{\circ}(111), 42.7^{\circ}(200), 61.9^{\circ}(220)$, and $74.5^{\circ}(311)$. Y-axis scale is the same, and zeros are shifted for clarity.

XRD was measured in Sample $\mathrm{C}$ before and after $700{ }^{\circ} \mathrm{C}$ annealing in $\mathrm{N}_{2}$ (Figure 3). For this experiment, TiN film was grown on a sapphire substrate for $30 \mathrm{~min}$. The purpose of this experiment was to investigate if $\mathrm{TiN}$ is converted to $\mathrm{TiO}_{2}$. Although the figure shows weaker XRD peaks after the annealing, there is no significant change in the XRD characteristics. The small peak (after the annealing) at $25^{\circ}$ is explained as (101) peak of $\mathrm{TiO}_{2}$ anatase (25.281 from JCPDS 21-1272).

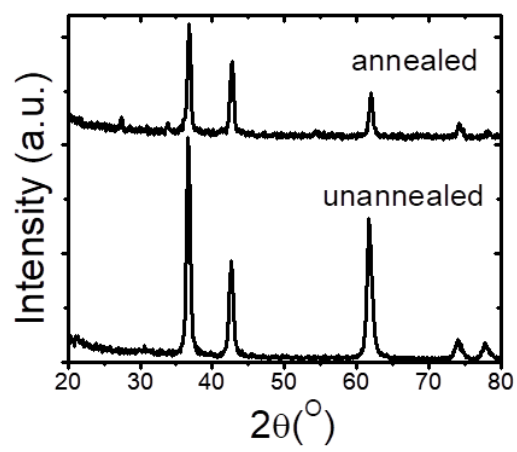

Figure 3. XRD data of Sample C, before and after $700{ }^{\circ} \mathrm{C}$ annealing in $\mathrm{N}_{2}$. TiN was grown on a sapphire substrate for $30 \mathrm{~min}$.

Rod resistances were measured after annealing in $\mathrm{N}_{2}$ (Figure 4). TiN was grown on the ceramic rods for $2 \mathrm{~h}$ using gas flows of Sample $\mathrm{C}$ in Table 1 . After growth, samples were annealed between 300 and $700^{\circ} \mathrm{C}$. The heating ramp was fixed at $120^{\circ} \mathrm{C} / \mathrm{min}$, and cool down was done without application of any heat. After the temperature reached the target value, the temperature was sustained for $5 \mathrm{~min}$. Fifteen samples were used for each temperature, and the average values of rod resistance were plotted (Figure 4). The effect of annealing for this figure is different from that in Figure 3, because gases trapped in the ceramic rods would react with TiN. Note that TiN in Figure 3 was grown on a sapphire substrate, and gas contamination during annealing is much smaller. Figure 4 shows that $400{ }^{\circ} \mathrm{C}$ annealing 
increased rod resistance by a large amount. In contrast, 500 and $600{ }^{\circ} \mathrm{C}$ annealing showed smaller resistance. This may be the result of reaction between $\mathrm{Ti}, \mathrm{N}$, and $\mathrm{O}$.

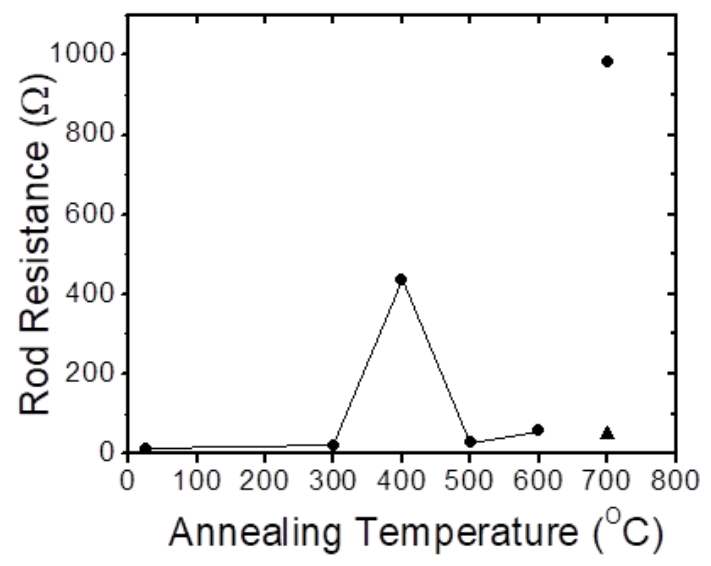

Figure 4. Rod resistances of Sample $\mathrm{C}$ grown on ceramic rods, as a function of annealing temperature. For $700{ }^{\circ} \mathrm{C}$ annealing, two types of temperature ramp were used. One type (circle) went up without any stop, and the other type (triangle) stopped at $400{ }^{\circ} \mathrm{C}$, before going up to $700{ }^{\circ} \mathrm{C}$.

Since the TiN film in these experiments was grown at $\sim 100{ }^{\circ} \mathrm{C}$, it would have excess $\mathrm{Ti}$ and $\mathrm{N}$, as well as vacancies. During annealing, the excess atoms may undergo $\mathrm{Ti}+\mathrm{N}$ or $\mathrm{Ti}+\mathrm{O}$ reactions, depending on annealing conditions [15]. At $400{ }^{\circ} \mathrm{C}$, trapped oxygen can escape from the ceramic rods, and excess $\mathrm{Ti}$ can react with this oxygen, resulting in a material with higher resistance, $\mathrm{TiO}_{2}$. At 500 and $600{ }^{\circ} \mathrm{C}$ annealing, however, it would be possible to have a $\mathrm{Ti}+\mathrm{N}$ reaction in addition to the $\mathrm{Ti}+\mathrm{O}$ reaction. $\mathrm{The} \mathrm{Ti}+\mathrm{N}$ reaction produces $\mathrm{TiN}$, which is of lower resistance than $\mathrm{TiO}_{2}$. At higher temperatures, it will be easier to remove the defects. This model can explain the lower resistance after annealing at 500 and $600{ }^{\circ} \mathrm{C}$, compared to the $400^{\circ} \mathrm{C}$ annealing.

For $700{ }^{\circ} \mathrm{C}$ annealing in Figure 4, two types of temperature ramps were used. One type (circle) went up to $700{ }^{\circ} \mathrm{C}$ without any stop, and the other type (triangle) stopped at $400{ }^{\circ} \mathrm{C}$ for $9 \mathrm{~min}$, before going up to $700{ }^{\circ} \mathrm{C}$. During the $400{ }^{\circ} \mathrm{C}$ stop, $\mathrm{N}_{2}$ gas was purged four times to remove trapped gases in the ceramic. After the normal $700{ }^{\circ} \mathrm{C}$ annealing, the rod resistance was increased to $982 \Omega$, which is 80 times larger than $12.3 \Omega$ of unannealed rods. The rods with the $400{ }^{\circ} \mathrm{C}$ stop showed $48.8 \Omega$, which is comparable to $56.7 \Omega$ of $600^{\circ} \mathrm{C}$ annealing.

\section{Discussion}

These experimental results showed that the introduction of hydrogen significantly improved the quality of TiN, as indicated by a lower resistance and strong XRD peaks. The exact mechanism of hydrogen function in TiN sputtering is unclear at this moment. Increases in high-energy tail in gold sputtering [10] and target surface conversion in metal oxide sputtering [11] were reported. These principles can be applied to our TiN sputtering.

One possible explanation for this phenomenon may be hydrogen-induced cracking in titanium (hydrogen embrittlement). When Ti is exposed to hydrogen gas at $\sim 300^{\circ} \mathrm{C}$, titanium hydride is formed at the surface, and Ti becomes brittle [16]. Hydride formation is an exothermic process, and it can develop rapidly under certain conditions. For example, the presence of energetic ions during sputtering growth can accelerate hydride formation. When a Ti target has hydride on the surface, Ti emission would increase, because dissociation from the target would be easier. Another possible explanation is that lower oxygen density would decrease the mid-course reaction. The function of hydrogen in TiN deposition has not been investigated in detail. A previous study has explored the use of hydrogen in plasma spray deposition [8], but the function of hydrogen was not discussed in detail. 
The high $\mathrm{N}$ concentration in TiN films grown without hydrogen needs more investigation. Although EDS showed a high N/Ti ratio, it does not necessarily mean that the target was coated with nitride. The target could also be covered with a thin layer of oxide. After growth, the target color was metallic, without any irregular patterns. Detailed analysis of the target surface will be needed.

\section{Conclusions}

This study showed that adding hydrogen during sputtering growth improves TiN quality. Since TiN in this study was grown on ceramic rods, this growth environment is different from an ideal condition. The hydrogen neutralized the effect of trapped gases, and high quality was confirmed by $X$-ray diffraction and energy dispersive spectroscopy. High temperature annealing, which is required for discrete electronic devices, caused a moderate increase in resistance when devices were preheated at $400{ }^{\circ} \mathrm{C}$ with $\mathrm{N}_{2}$ purging. These results showed that TiN could be grown on ceramic substrates for discrete device applications.

Author Contributions: Conceptualization, D.K. (Doowon Kang) and J.J.; TiN Film Growth, J.C. and W.J.; Measurements, J.J.; Device Test, D.K. (Dongjin Kang); Methodology, J.J.; Validation, D.K. (Doowon Kang); Writing-Original Draft Preparation, D.K. (Dongjin Kang) and J.J.; Writing-Review and Editing, J.J.; Supervision, D.K. (Doowon Kang).

Funding: This research received no external funding.

Acknowledgments: The authors are grateful to Si Ra Bae of the Center for Material Characterization at Ajou University for X-ray measurements. The authors are also grateful to Sally Jo for critical reading of the manuscript.

Conflicts of Interest: The authors declare no conflict of interest.

\section{References}

1. Westlinder, J.; Schram, T.; Pantisano, L.; Cartier, E.; Kerber, A.; Lujan, G.S.; Olsson, J.; Groeseneken, G. On the thermal stability of atomic layer deposited TiN as gate electrode in MOS devices. IEEE Electron Device Lett. 2003, 24, 550-552. [CrossRef]

2. Achour, A.; Chaker, M.; Achour, H.; Arman, A.; Islam, M.; Mardani, M.; Boujtita, M.; Le Brizoual, L.; Djouadi, M.A.; Brousse, T. Role of nitrogen doping at the surface of titanium nitride thin films towards capacitive charge storage enhancement. J. Power Sources 2017, 359, 349-354. [CrossRef]

3. Wang, S.; Kravchyk, K.V.; Filippin, A.N.; Widmer, R.; Tiwari, A.N.; Buecheler, S.; Bodnarchuk, M.I.; Kovalenko, M.V. Overcoming the high-voltage limitations of Li-ion batteries using a titanium nitride current collector. ACS Appl. Energy Mater. 2019, 2, 974-978. [CrossRef]

4. Lim, W.G.; Jo, C.; Cho, A.; Hwang, J.; Kim, S.; Han, J.W.; Lee, J. Approaching ultrastable high-rate Li-S batteries through hierarchically porous titanium nitride synthesized by multiscale phase separation. Adv. Mater. 2019, 31, 1806547. [CrossRef] [PubMed]

5. Jeyachandran, Y.L.; Narayandass, S.K.; Mangalaraj, D.; Areva, S.; Mielczarski, J.A. Properties of titanium nitride films prepared by direct current magnetron sputtering. Mater. Sci. Eng. 2007, 445-446, 223-236. [CrossRef]

6. Jithin, M.; Kolla, L.G.; Vikram, G.N.V.R.; Udayashankar, N.K.; Mohan, S. Pulsed DC magnetron sputtered titanium nitride thin films for localized heating applications in MEMS devices. Sens. Actuators A 2018, 272, 199-205. [CrossRef]

7. Rasic, D.; Sachan, R.; Chisholm, M.F.; Prater, J.; Narayan, J. Room temperature growth of epitaxial titanium nitride films by pulsed laser deposition. Cryst. Growth Des. 2017, 17, 6634-6640. [CrossRef]

8. Fan, X.; Darut, G.; Planche, M.P.; Feng, X.; Liao, H.; Montavon, G. Characterizations of composite titanium nitride coatings deposited by very low-pressure plasma spraying. J. Therm. Spray Technol. 2019, 28, 265-272. [CrossRef]

9. Yoo, D.; Jeon, W.; Kim, J.; Meng, J.; Yang, Y.; Jo, J. ZnO thin-film transistor grown by RF sputtering using Zn metal target and oxidizer pulsing. J. Ceram. Soc. Jpn. 2017, 125, 112-117. [CrossRef]

10. Budtz-Jørgensen, C.V.; Kringhøj, P.; Bøttiger, J. The critical role of hydrogen for physical sputtering with Ar- $\mathrm{H}_{2}$ glow discharges. Surf. Coat. Technol. 1999, 116-119, 938-943. [CrossRef]

11. Ondok, V.; Musil, J. Effect of hydrogen on reactive sputtering of transparent oxide films. Plasma Process. Polym. 2007, 4, S319-S324. [CrossRef] 
12. Gray, B.M.; Hector, A.L.; Jura, M.; Owen, J.R.; Whittam, J. Effect of oxidative surface treatments on charge storage at titanium nitride surfaces for supercapacitor applications. J. Mater. Chem. A 2017, 5, 4550-4559. [CrossRef]

13. Lee, Y.; George, S.M. Thermal atomic layer etching of titanium nitride using sequential, self-limiting reactions: Oxidation to $\mathrm{TiO}_{2}$ and fluorination to volatile $\mathrm{TiF}_{4}$. Chem. Mater. 2017, 29, 8202-8210. [CrossRef]

14. Adachi, J.; Urakawa, J.; Sumi, T.; Kitazume, T. ESD Protection Device. US Patent No. 8,238,069, 7 August 2012.

15. Ponon, N.K.; Appleby, D.J.R.; Arac, E.; King, P.J.; Ganti, S.; Kwa, K.S.K.; O’Neill, A. Effect of deposition conditions and post deposition anneal on reactively sputtered titanium nitride thin films. Thin Solid Films 2015, 578, 31-37. [CrossRef]

16. Setoyama, D.; Matsunaga, J.; Muta, H.; Uno, M.; Yamanaka, S. Mechanical properties of titanium hydride. J. Alloy. Compd. 2004, 381, 215-220. [CrossRef]

(C) 2019 by the authors. Licensee MDPI, Basel, Switzerland. This article is an open access article distributed under the terms and conditions of the Creative Commons Attribution (CC BY) license (http://creativecommons.org/licenses/by/4.0/). 